\title{
Managing patients with heart failure: contemporary real-world experience
}

\author{
Muhammad Siddiqui ${ }^{1 *} \mathbb{B}$, Christopher Ripplinger ${ }^{2}$, Hafsah Chalchal $^{2}$ and Dakshina Murthy ${ }^{2,3}$
}

\begin{abstract}
Objective: Heart failure (HF) is a chronic disease with growing numbers of patients and a significant compromise in quality of life and high mortality. The main purpose of this study was to evaluate the current practices in managing patients with HF among patients admitted to the hospital and discharged with a primary diagnosis of HF and patients managed in the heart function clinic.

Results: This study is a retrospective chart review of patients admitted to the hospital and discharged with a primary diagnosis of HF. A total of 448 patient charts were reviewed, of which 173 patients were in the hospital group and 275 patients in the Clinic group. 278 (62.1\%) were men, and 170 (37.9\%) were women. The Clinic group of patients were significantly received guideline-directed medical therapy (Beta-blockers, Angiotensin-converting enzyme inhibitors, Angiotensin receptor blockers, Diuretics, Mineralocorticoid receptor antagonists $-p<0.001$ ). The Clinic group of patients $(17.1 \%)$ were significantly less re-hospitalized $(p<0.001)$ compared to the Hospital group $(28 \%)$ at 180 days. Physician led multidisciplinary Heart function clinics have better adherence to guideline directed medical therapy and significantly lower rates of re-hospitalization thereby providing cost effective heart failure management with usual care.
\end{abstract}

Keywords: Congestive HF, Management, Re-hospitalization

\section{Introduction}

Heart failure (HF) is a major medical illness that affects both people and healthcare systems worldwide [1, 2]. HF is an emergent healthcare burden and one of the principal causes of hospitalizations and re-admission; it is expected to increase in prevalence over the next decade [2]. About 669,600 (3.6\%) Canadian adults aged 40 years and older live with diagnosed HF, and approximately 92,900 (5.2 per 1000) Canadian adults aged 40 years and older received a new diagnosis of HF [3]. HF often does not occur in isolation and is often associated with other comorbidities, including hypertension, diabetes, coronary artery disease, and Valvular disease. Although

\footnotetext{
*Correspondence: muhammad.siddiqui@saskhealthauthority.ca

${ }^{1}$ Department of Research, Saskatchewan Health Authority, Regina, SK, Canada

Full list of author information is available at the end of the article
}

various HF treatments have been developed, patients are often left with HF and discharged home diagnosis without clear instructions on what other lifestyle factors should be considered, such as diet, exercise, and smoking. This has led to the development of heart function clinics, which utilizes a multidisciplinary approach to HF by including cardiologists, dieticians, pharmacists, and nurses into the patients' circle of care.

Among heart HF patients, poor adherence to medications is a common problem. Inadequate compliance leads to increased HF exacerbations, reduced physical function, and a higher risk for hospital admission and death. Interventions to enhance medication compliance in HF patients have substantial effects on reducing readmissions and decreasing mortality. Medication observance should be tackled in regular follow-up visits with HF patients, and interventions to improve compliance should be crucial for HF self-care programs [4]. 
To help out and manage symptoms, HF patients are taught self-care strategies, maintain physical functioning, and prevent symptom exacerbations and deterioration of disease that could cause hospitalization or death. Medication is a critical part of HF management, and following medication regimes is a crucial behavior in HF self-care. Unfortunately, HF patients' adherence to medication is low, which negatively affects clinical outcomes and leading to exacerbations of HF, reduces physical function, and causes a higher risk for hospital admission and death $[5$, 6].

Cardiovascular guideline-directed therapy has previously been shown to improve survival, reduce readmissions to hospital, and improve life quality for those diagnosed with HF $[2,7]$. Preventing re-admissions for HF patients is an increasing priority for clinicians, researchers, and various stakeholders. The purpose of this study was to retrospectively review patients being followed through the heart function clinic with a primary diagnosis of congestive HF. In doing so, we aim to analyze the current practice of diagnosis and management of congestive HF alongside re-admission and mortality rates while being followed up through the heart function clinic.

\section{Main text \\ Methods}

This study is a retrospective chart review of Heart Function Clinic, and patients admitted to the hospital and discharged with a primary diagnosis of HF from medicine department within an academic tertiary-care hospital system from Jan 2016 to July 2018. Only patients being recorded due to CHF's secondary cause, rather than congenital, were selected for this study. Patient data were retrieved from their respective charts and electronic medical records. Data on demographics, comorbidities, medication history, and re-hospitalization up to 180 days were obtained for both groups. Guideline directed medical therapy and re-hospitalization rates were the main focus of comparison between the two groups. Readmissions to hospital and emergency room visits were detected on Sunrise Clinical Manager (SCM) electronic medical records and were separated based on the cause of re-admission.

One medical student reviewed charts of patients in the hospital group, and a second medical student reviewed charts of patients in the clinic group. The study cohort was identified using clinical data from the electronic health record. All data extracted from the patient records were recorded in a de-identified manner in a passwordprotected file and USB drive. Any information collected for the study was de-identified by assigning a unique study identification number to maintain confidentiality.
All data was labeled with the participant ID, and no other identifying information was included in collecting data. Data were analyzed on a de-identified dataset to protect patient confidentiality.

For this study, it was impracticable to obtained informed consent because the participants may be deceased or have moved. Getting permission from family members might be problematic (e.g., due to change of address), not feasible because of a lack of funding and time, potentially disturbing to the family members. The research ethics board approved a waiver of informed consent as this study meets criteria a-f of Article 5.5 in the Tri-Council Policy Statement-2 (TCPS).

Statistical analysis was performed using SPSS Statistics software (Version 22.0. Armonk, NY: IBM Corp.). Data were expressed in frequencies, mean, and percentages. Chi-square test was used as a test of significance to compare differences between groups for categorical data, and $\mathrm{t}$-test was used for continuous data. Significance was set at $\mathrm{p}<0.05$ level.

\section{Results}

A total of 448 patient charts were reviewed, of which 173 patients were in the hospital group and 275 patients in the Clinic group. The mean age of included patients was $71.50 \pm 13.9$ years, and $170(37.9 \%)$ were female. 255 (56.9\%) of patients were older than 75 years of age. Our cohort's comorbid conditions were prevalent: $65.2 \%$ had hypertension, $33.5 \%$ had diabetes, $60.5 \%$ had hypercholesterolemia, and $52.2 \%$ had no history of smoking. Majority of study patients were with reduced ejection fraction (Table 1).

Most patients were prescribed ACE inhibitors (44.5\% hospital gr; $65.8 \%$ clinic gr) or ARB (20.8\% hospital gr; $20.7 \%$ clinic gr) before, and beta-blockers (76\% hospital gr; $90.5 \%$ clinic gr) (Table 2). Furosemide was prescribed to $94.2 \%$ of a hospital patient and $66.9 \%$ of an HF clinic which evidently indicates that the two cohorts are different in disease stage and clinical stability. Almost two third (70.5\%) of patients were not prescribed any mineralocorticoid; Aldactone was prescribed to $2.3 \%$ of hospital patients at discharge and $45.5 \%$ of heart clinic patients. In study population, only one heart function clinic patient had received Ivabradine and three patients received Angiotensin Receptor Neprilysin Inhibitor. The Clinic groups of patients were significantly on guideline-directed medical therapy (Beta-blockers, Angiotensin-converting enzyme inhibitors, Angiotensin receptor blockers, Diuretics, Mineralocorticoid receptor antagonists $-\mathrm{p}<0.001)$.

Among 448 patients, concerning re-admissions to hospital, patients were less likely to be admitted after 1 month (1.5\%) and 6 months (5.5\%) of their initial visit 
Table 1 Participants selected risk factors $(n=448)$

\begin{tabular}{|c|c|c|c|c|}
\hline & $\begin{array}{l}\text { Total-448 } \\
\text { n (\%) }\end{array}$ & Hospital Group-173 n (\%) & Clinic Group-275 n (\%) & P-Value \\
\hline Age & & & & $<0.001$ \\
\hline$\leq 75$ years & $255(56.9)$ & $71(41)$ & $184(66.9)$ & \\
\hline$>75$ years & $193(43.1)$ & $102(59)$ & $91(33.1)$ & \\
\hline Gender & & & & 0.001 \\
\hline Coronary artery disease & $217(48.4)$ & $80(46.2)$ & $137(49.8)$ & 0.46 \\
\hline Diabetes & $150(33.5)$ & $67(38.7)$ & $83(30.2)$ & 0.06 \\
\hline Hypercholesterolemia & $271(60.5)$ & $74(42.8)$ & $197(71.6)$ & $<0.001$ \\
\hline Hypertension & $292(65.2)$ & $135(78)$ & $157(57.1)$ & $<0.001$ \\
\hline Peripheral vascular disease & $27(6)$ & $18(10.4)$ & $9(3.3)$ & 0.02 \\
\hline Coronary artery bypass graft & $98(21.9)$ & $37(21.4)$ & $61(22.2)$ & 0.84 \\
\hline Left ventricular hypertrophy (ECG) & $52(11.6)$ & $22(12.7)$ & $30(10.9)$ & 0.56 \\
\hline Current smoker & $70(15.6)$ & $25(15.5)$ & $45(16.4)$ & $<0.001$ \\
\hline Ejection fraction & & & & $<0.001$ \\
\hline Not done & $57(12.7)$ & $57(32.9)$ & 0 & \\
\hline Normal & $54(12.1)$ & $41(23.7)$ & $13(4.7)$ & \\
\hline Reduced $<50$ & $337(75.2)$ & $75(43.2)$ & $262(95.3)$ & \\
\hline Angiography & & & & $<0.001$ \\
\hline No disease & $70(15.6)$ & $12(6.9)$ & $58(21.1)$ & \\
\hline Single vessel disease & $56(12.5)$ & $11(6.4)$ & $45(16.4)$ & \\
\hline Double vessel disease & $34(7.6)$ & $11(6.4)$ & $23(8.4)$ & \\
\hline Tipple vessel disease & $50(11.2)$ & $9(5.2)$ & $41(14.9)$ & \\
\hline Unknown & $234(52.2)$ & $126(72.8)$ & $108(39.3)$ & \\
\hline Left main disease & $4(1.3)$ & $4(2.3)$ & 0 & \\
\hline
\end{tabular}

Table 2 Participants medication of HF $(n=448)$

\begin{tabular}{|c|c|c|c|c|}
\hline & $\begin{array}{l}\text { Total-448 } \\
\text { n (\%) }\end{array}$ & $\begin{array}{l}\text { Hospital Group-173 } \\
\text { n (\%) }\end{array}$ & $\begin{array}{l}\text { Clinic Group-275 } \\
\text { n (\%) }\end{array}$ & P-Value \\
\hline Beta-blockers & $381(85)$ & $132(76.3)$ & $249(90.5)$ & $<0.001$ \\
\hline Hydralazine & $33(7.4)$ & $26(15)$ & $7(2.5)$ & $<0.001$ \\
\hline Nitrates & $139(31)$ & $85(49.1)$ & $54(19.6)$ & $<0.001$ \\
\hline Diuretics & $347(77.5)$ & $163(94.2)$ & $184(66.9)$ & $<0.001$ \\
\hline MRA & & & & $<0.001$ \\
\hline No & $316(70.5)$ & $169(97.7)$ & $147(53.5)$ & \\
\hline Aldactone & $129(28.8)$ & $4(2.3)$ & $125(45.5)$ & \\
\hline Eplerenone & $3(0.7)$ & 0 & $3(1.1)$ & \\
\hline ARBs \& ACE inhibitors & & & & $<0.001$ \\
\hline No & $97(21.6)$ & $60(34.7)$ & $37(13.5)$ & \\
\hline ACE inhibitors & $258(57.6)$ & $77(44.5)$ & $181(65.8)$ & \\
\hline ARBs & $93(20.8)$ & $36(20.8)$ & $57(20.7)$ & \\
\hline
\end{tabular}

to the heart function clinic (Fig. 1). Also, most patients were not re-admitted at any time following their initial assessment at the heart function clinic (82.9\%) and among patients admitted to the hospital and discharged with a primary diagnosis of HF (67.6\%). The Clinic group of patients (17.1\%) were significantly less likely to be rehospitalized $(\mathrm{p}<0.001)$ compared to the Hospital group $(28 \%)$ at 180 days. 


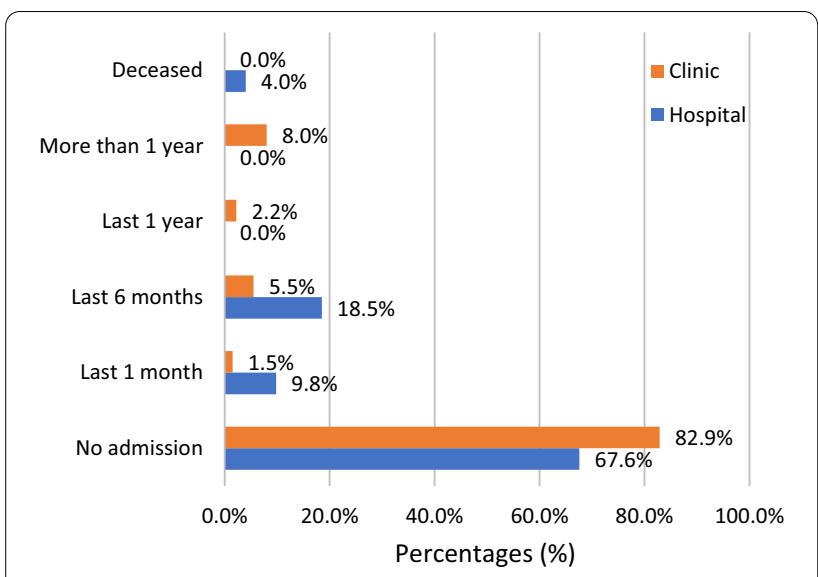

Fig. 1 Patient's outcomes with a primary diagnosis of HF

\section{Discussion}

This retrospective chart review study revealed interesting outcomes. Diagnosis and HF management are highly heterogeneous and complex and often yield mixed results in different HF populations [8-10]. Our center Heart Failure intervention program is leading by a Cardiologist with expertise in HF and cardiac specialist nurse. Additionally, Psychiatric interventions plus cardiac rehabilitation are also included in the program. Mainly, local and global left ventricle progressive dilatation, and dysfunction, due to secondary myocardial impairment in patients with heart failure and ischemic myocardiopathy [11]. In these patients, cardiac remodeling can lead to a decline in exercise ability and a rise in HF hospitalization [12].

Great interest has been shown by policymakers and researchers in the idea of averting re-admission rates among HF patients. The 30-day re-admission rate measures hospital performance; in the United States, it has been linked to financial penalties [22]. Moreover, at 6-month follow-up, re-admission within 30-day is coupled with a poor prognosis [23]. Results of a multicenter study conducted in 171 centers in which 43,143 patients were treated showed that the hospitals had a higher 1-year all-cause re-admission rate $(54.7 \%)$ with high riskadjusted 30-day re-admission rates (59.1\%) [24]. In this study Clinic group of patients $(17.1 \%)$ were significantly less likely to be re-hospitalized $(\mathrm{p}<0.001)$ compared to the Hospital group (28\%) at 180 days. A study conducted by Chen et al. [13] revealed that heart failure management programs had a lower 1-year re-admission rate $(29.67 \%)$ than patients who dealt with regular treatment (38.5\%). In other countries of HF registries, such as the HF outcome registry in India, the 1-year re-admission rate was 30.1\% [14], and in the Saudi Arabia registry, it was $36 \%$ [15]. On the other hand, in patients hospitalized with acute HF in Europe, the EHFS-2 registry shows a 1-year mortality rate of $21.9 \%$ [16]. The HF registry indicates a $24.4 \%$ mortality rate in 1 year in India [14]. In the United Kingdom, a population-based cohort study conducted between 2000 and 2017 revealed that for people with a new HF diagnosis, the overall 1-year mortality decreased from 25.8 to $19.2 \%$ between 2000 and 2016 [17]. In comparison, our study's hospital group had a 1 -year mortality rate of $4 \%$, and the heart function clinic had $0 \%$.

Mineralocorticoid receptor antagonist (MRA) therapy is one component of treating patients with systolic HF. Clinical trials have demonstrated that MRA therapy reduces morbidity and mortality in HF patients due to left ventricular systolic dysfunction. Our study results have revealed that MRA was underutilized (23\%) in patients admitted to the hospital and discharged with HF's primary diagnosis. Overall, this study showed MRA's underutilization, which is consistent with prior studies, predominantly in acutely decompensated HF patients [18-20]. MRA's due to the risk of developing hyperkalemia and a combination of providers [20]. Other impediments consist of ambiguity about who should prescribe them in transitions of care, physician's expertise about patient suitability, apprehensions about adverse effects, polypharmacy, follow-up observance, and noncompliance $[21,22]$. In patients with underlying chronic kidney disease, timely follow-up laboratory testing is critical in reducing hyperkalemia risk [23, 24]. Appropriate laboratory follow-up increases to $25.2 \%$ (inpatient MRA initiation) from $2.8 \%$ (outpatient MRA initiation) [25].

The aims of this study were focused on adverse outcomes. Therefore, we don't have a cost analysis for this study. We agree it's an essential issue for the heart function clinic program, and the results will provide helpful information for policy decision-makers. Comparisons with the hospital discharged group showed that the heart function clinic reduced recurrent events of the hospitalization. It is believed that the disease management program would be more cost-effective by decreasing the HF re-admission rate. Study results concluded that:

- Patients treated in the heart function clinic are treated accorded HF guidelines.

- All efforts should be made to guarantee that any patient admitted due to HF has an ultrasound done during the hospitalization or the first 2 weeks after discharge to classify them better and treat them according to guidelines.

- Protocols and pathways to refer patients to the HF clinic need to be implemented. 


\section{Limitations}

One of the core limitations of this study is that the patients studied were from a single tertiary care center. The study developed and evaluated the effectiveness of a heart function clinic managing HF patients over a 180 days follow-up period. Hence, the study results may not be generalizable to the spectrum of HF patients. Further investigation is warranted to assess the effectiveness of a specialized HF management program in a multicentre setup with a more extended follow-up period. Another limitation is the retrospective type of data. A number of situations may have been missed because the data was not transliterated or easily found in patients' charts. This study did not report cost or resource utilization for the cohort of patients. Thus, it cannot come to any conclusions regarding the unit's utility from a system perspective. Future research might explore what this means from a system perspective. We did not explore Sodium-glucose co-transporter 2 (SGLT2) inhibitors in this study, which have been shown to reduce heart failure hospitalizations in patients with heart failure with and without diabetes.

Physician specialist-led multidisciplinary heart function clinic managed HF patients better implement guideline-directed medical therapy and lower re-hospitalization rates than those treated by non-specialist Physicians. Comparisons with the hospital discharged group showed that the heart function clinic reduced recurrent events of the hospitalization.

\section{Abbreviations \\ HF: Heart failure; REB: Research ethics board; SCM: Sunrise Clinical Man- ager; TCPS: Tri-Council Policy Statement; MRA: Mineralocorticoid receptor antagonist.}

\section{Acknowledgements}

We recognize the College of Medicine, University of Saskatchewan Dean's Summer Research Projects Program, which facilitates medical student's exposure to scientific research.

\section{Authors' contributions}

DM conceived the study. CR and HC have collected the data \& MAS analyzed the data. MAS drafted the manuscript while DM, CR, HC, and MAS revised and reviewed the whole document. All authors read and approved the final manuscript.

\section{Funding}

No funding was obtained.

\section{Availability of data and materials}

The datasets during and/or analyzed during the current study are available from the corresponding author on reasonable request.

\section{Declarations}

\section{Ethics approval and consent to participate}

The study protocol was approved by the former Regina Research Ethics Board, Saskatchewan Health Authority, Regina, SK, Canada. Waiver of informed consent was approved by the research ethics board as this study meets criteria a-f of Article 5.5 in the Tri-Council Policy Statement-2 (TCPS).

Consent for publication

Not applicable.

\section{Competing interests}

The authors declare that they have no competing interests.

\section{Author details}

${ }^{1}$ Department of Research, Saskatchewan Health Authority, Regina, SK, Canada. ${ }^{2}$ College of Medicine, University of Saskatchewan, Saskatoon, SK, Canada.

${ }^{3}$ Division of Cardiology, Regina General Hospital, Saskatchewan Health Authority, Regina, SK, Canada.

Received: 13 November 2020 Accepted: 31 January 2022

Published online: 10 February 2022

\section{References}

1. Blair JE, Huffman M, Shah SJ. Heart failure in North America. Curr Cardiol Rev. 2013;9(2):128-46.

2. Gandhi S, Mosleh W, Sharma UC, Demers C, Farkouh ME, Schwalm JD. Multidisciplinary heart failure clinics are associated with lower heart failure hospitalization and mortality: systematic review and meta-analysis. Can J Cardiol. 2017;33(10):1237-44.

3. Heart disease in Canada. Highlights from the Canadian chronic disease surveillance system. Public Health Agency of Canada. [Online]. https:// www.canada.ca/en/public-health/services/publications/diseases-condi tions/heart-disease-canada-fact-sheet.html.

4. Ruppar TM, Cooper PS, Mehr DR, Delgado JM, Dunbar-Jacob JM. Medication adherence interventions improve heart failure mortality and readmission rates: systematic review and meta-analysis of controlled trials. J Am Heart Assoc. 2016;5(6):e002606

5. McAlister FA, Stewart S, Ferrua S, McMurray JJ. Multidisciplinary strategies for the management of heart failure patients at high risk for admission: a systematic review of randomized trials. J Am Coll Cardiol. 2004;44(4):810-9.

6. Moher D, Liberati A, Tetzlaff J, Altman DG, The PG. Preferred reporting items for systematic reviews and meta-analyses: the PRISMA statement. PLOS Med. 2009;6(7):e1000097.

7. Mirra M, Vitulano G, Virtuoso N, Tufano N, D’Auria F, De Angelis S, Giudice R, Lambiase A, Gigantino A, Piscione F. Heart failure in a dedicated outpatient clinic: results after 58 month follow-up. Can it be enough? Transl Med Uni. 2014;11:59-62.

8. Atienza F, Anguita M, Martinez-Alzamora N, Osca J, Ojeda S, Almenar L, Ridocci F, Valles F, de Velasco JA. Multicenter randomized trial of a comprehensive hospital discharge and outpatient heart failure management program. Eur J Heart Fail. 2004;6(5):643-52.

9. Capomolla S, Febo O, Ceresa M, Caporotondi A, Guazzotti G, La Rovere M, Ferrari M, Lenta F, Baldin S, Vaccarini C, et al. Cost/utility ratio in chronic heart failure: comparison between heart failure management program delivered by day-hospital and usual care. J Am Coll Cardiol. 2002;40(7):1259-66.

10. Mejhert M, Kahan T, Persson H, Edner M. Limited long term effects of a management programme for heart failure. Heart. 2004;90(9):1010-5.

11. Gaudron P, Eilles C, Kugler I, Ertl G. Progressive left ventricular dysfunction and remodeling after myocardial infarction. Potential mechanisms and early predictors. Circulation. 1993;87(3):755-63.

12. Goldstein S, Sharov VG, Cook JM, Sabbah HN. Ventricular remodeling: insights from pharmacologic interventions with angiotensin-converting enzyme inhibitors. Mol Cell Biochem. 1995;147(1-2):51-5.

13. Chen S-M, Fang Y-N, Wang L-Y, Wu M-K, Wu P-J, Yang T-H, Chen Y-L, Hang C-L. Impact of multidisciplinary treatment strategy on systolic heart failure outcome. BMC Cardiovasc Disord. 2019;19(1):220.

14. Senni M, Gavazzi A, Oliva F, Mortara A, Urso R, Pozzoli M, Metra M, Lucci D, Gonzini L, Cirrincione V et al. In-hospital and 1-year outcomes of acute heart failure patients according to presentation (de novo vs. worsening) and ejection fraction. Results from IN-HF Outcome Registry. Int J Cardiol. 2014;173(2):163-9. 
15. Salem K, Fallata D, ElSebaie M, Montasser A, ElGedamy K, ElKhateeb O. Congestive heart failure disease management program: 1-Year population experience from a tertiary center heart failure registry in Saudi Arabia. J Saudi Heart Assoc. 2017;29(2):90-5.

16. Harjola VP, Follath F, Nieminen MS, Brutsaert D, Dickstein K, Drexler H, Hochadel M, Komajda M, Lopez-Sendon JL, Ponikowski P, et al. Characteristics, outcomes, and predictors of mortality at 3 months and 1 year in patients hospitalized for acute heart failure. Eur $\mathrm{J}$ Heart Fail. 2010;12(3):239-48.

17. Taylor CJ, Ordonez-Mena JM, Roalfe AK, Lay-Flurrie S, Jones NR, Marshall T, Hobbs FDR. Trends in survival after a diagnosis of heart failure in the United Kingdom 2000-2017: a population-based cohort study. BMJ. 2019;364:1223.

18. Ferreira JP, Rossignol P, Machu JL, Sharma A, Girerd N, Anker SD, Cleland JG, Dickstein K, Filippatos G, Hillege HL, et al. Mineralocorticoid receptor antagonist pattern of use in heart failure with reduced ejection fraction: findings from BIOSTAT-CHF. Eur J Heart Fail. 2017;19(10):1284-93.

19. Fonarow GC, Albert NM, Curtis AB, Gheorghiade M, Liu Y, Mehra MR, O'Connor CM, Reynolds D, Walsh MN, Yancy CW. Incremental reduction in risk of death associated with use of guideline-recommended therapies in patients with heart failure: a nested case-control analysis of IMPROVE HF. J Am Heart Assoc. 2012;1 (1):16-26.

20. Hernandez AF, Mi X, Hammill BG, Hammill SC, Heidenreich PA, Masoudi $F A$, Qualls $L G$, Peterson ED, Fonarow GC, Curtis LH. Associations between aldosterone antagonist therapy and risks of mortality and re-admission among patients with heart failure and reduced ejection fraction. JAMA. 2012;308(20):2097-107.

21. Dev S, Hoffman TK, Kavalieratos D, Heidenreich P, Wu WC, Schwenke DC Tracy SJ. Barriers to adoption of mineralocorticoid receptor antagonists in patients with heart failure: a mixed-methods study. J Am Heart Assoc. 2016;5(3):e002493.

22. Hirt MN, Muttardi A, Helms TM, van den Bussche H, Eschenhagen T. General practitioners' adherence to chronic heart failure guidelines regarding medication: the GP-HF study. Clin Res Cardiol. 2016;105(5):441-50.

23. Pitt B, Rossignol P. The safety of mineralocorticoid receptor antagonists (MRAs) in patients with heart failure. Expert Opin Drug Saf. 2016;15(5):659-65.

24. Vukadinovic D, Lavall D, Vukadinovic AN, Pitt B, Wagenpfeil S, Bohm M. True rate of mineralocorticoid receptor antagonists-related hyperkalemia in placebo-controlled trials: a meta-analysis. Am Heart J. 2017;188:99-108.

25. Cooper LB, Hammill BG, Peterson ED, Pitt B, Maciejewski ML, Curtis LH, Hernandez AF. Characterization of mineralocorticoid receptor antagonist therapy initiation in high-risk patients with heart failure. Circ Cardiovasc Qual Outcomes. 2017;10(1):e002946

\section{Publisher's Note}

Springer Nature remains neutral with regard to jurisdictional claims in published maps and institutional affiliations.

Ready to submit your research? Choose BMC and benefit from:

- fast, convenient online submission

- thorough peer review by experienced researchers in your field

- rapid publication on acceptance

- support for research data, including large and complex data types

- gold Open Access which fosters wider collaboration and increased citations

- maximum visibility for your research: over $100 \mathrm{M}$ website views per year

At BMC, research is always in progress.

Learn more biomedcentral.com/submissions 